\title{
Automated System for Operational Monitoring of Technological Processes in Cotton Enterprises
}

\section{Rosulov RK* and Muhamadiev DM}

Tashkent Institute of Textile and Light Industry, Tashkent, Uzbekistan

\section{Introduction}

Control object is a collection of hardware (machines, machines, equipment, vehicles), which requires the organization of specially organized actions to achieve the desired results of operation $[1,2]$.

The goal of process automation is to improve the processing of cotton technical and economic indicators and the reliability of the technological machines through automatic and automated maintenance of the most efficient mode of technological processing of raw cotton. The optimal technological regime of processing raw cotton should be carried out within the framework of planned and technological constraints with possibly fewer operating personnel.

The main indicator of utilizable processing of raw cotton is given minimum energy costs [3]. For improved economic performance processing of raw cotton shall be achieved through:

- Optimization of operation of machines for drying and cleaning of cotton from small and large litter;

- Optimizing the operation of technological machines ginning and maintain;

- Rational performance of these machines;

- Increase productivity staff;

- Rational use of installed capacity and energy savings;

- Increasing the time between overhauls of technological equipment and prevent it from damage;

- Improving the quality of the cotton fiber, lint and seeds.

To control the humidity, and cotton production line capacity at the 1st (lowest) level control (automation) must have the following composition hardware;

- To control the humidity of cotton and performance of the drying drum: humidity sensors cotton $\varphi$ and $\varphi_{\mathrm{h}}$, temperature sensor drying agent $t$, pressure sensor before exhauster Pd;

- Performance management saw Gina: current sensors motor saw cylinders I1 and I2, pressure sensors airbags pickup fiber P1 and P2;

- Regulating device - using electric, morning device controller us Norman device is designed to generate current signals I, proportional to the measured physical quantity and lying in the range $4(20 \mathrm{~mA})$.

As a result of the approximation process parameters recommended drying Ginning of cotton [3], the following mathematical model: A confidence factor $\mathrm{R}^{2}=0.9953$ for the temperature of the drying agent, $0^{\circ} \mathrm{C}$, depending on the moisture content of cotton, \% [4]:

$y=37.452 e^{0107 x}$

- a factor of reliability - $\mathrm{R}^{2}=0.9739$ for dilution before exhauster, Pa depending on the moisture content of cotton, $\%[4]$ :

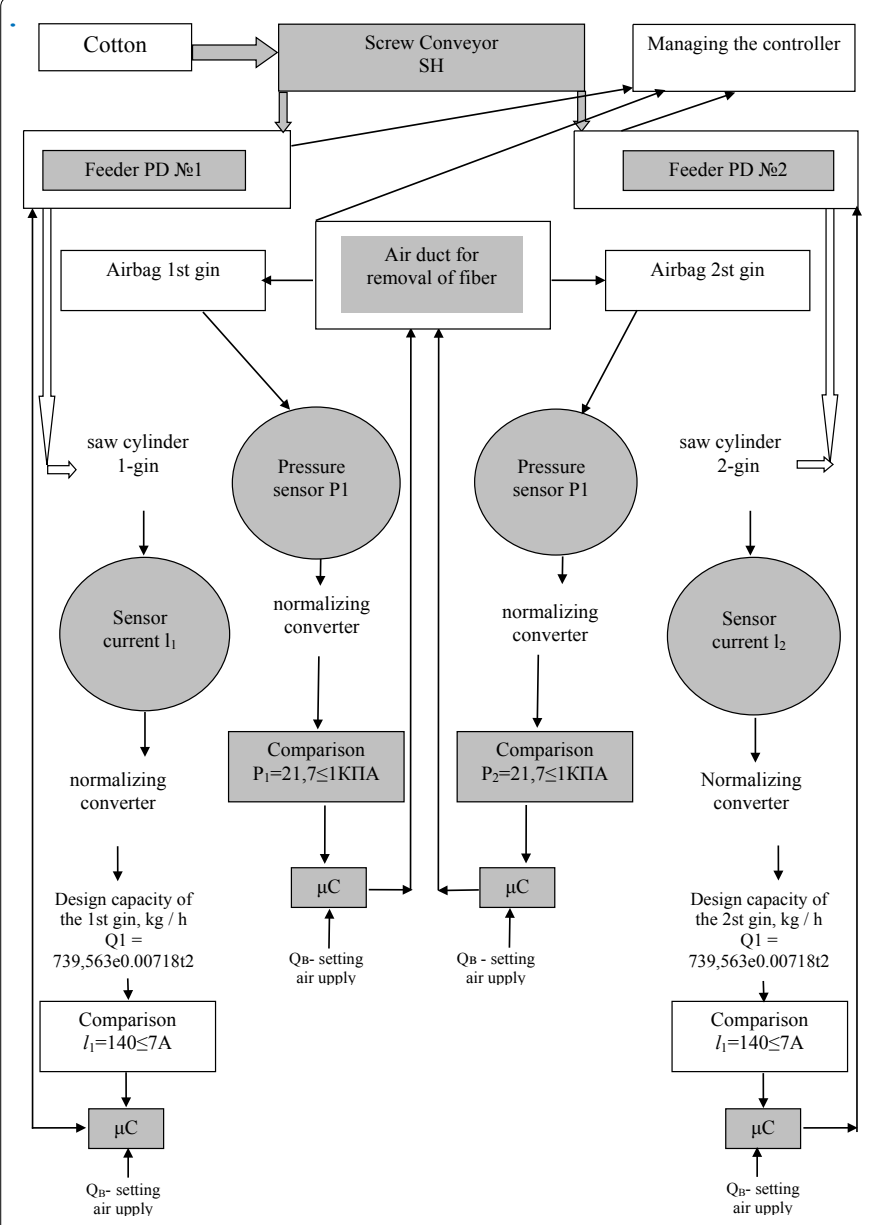

Figure 1: The system of moisture management and performance of the drying drum.

$\mathrm{y}=325,39 \mathrm{e}^{0,021 \mathrm{x}}$

- a confidence factor R2=0,9933 performance gin $\mathrm{kg} / \mathrm{hour}$, depending on the motor current of the saw cylinder, and [4]:

$y=739.563 e^{0.00718 x}$

*Corresponding author: Rosulov RK, Tashkent Institute of Textile and Light Industry, Tashkent, Uzbekistan, E-mail: rasulov.ruzimurad@mail.ru

Received April 27, 2015; Accepted May 30, 2015; Published July 15, 2015

Citation: Rosulov RK, Muhamadiev DM (2015) Automated System for Operationa Monitoring of Technological Processes in Cotton Enterprises. J Textile Sci Eng 5: 202. doi: $10.4172 / 2165-8064.1000202$

Copyright: (c) 2015 Rosulov RK, et al. This is an open-access article distributed under the terms of the Creative Commons Attribution License, which permits unrestricted use, distribution, and reproduction in any medium, provided the original author and source are credited. 
Citation: Rosulov RK, Muhamadiev DM (2015) Automated System for Operational Monitoring of Technological Processes in Cotton Enterprises. J Textile Sci Eng 5: 202. doi:10.4172/2165-8064.1000202

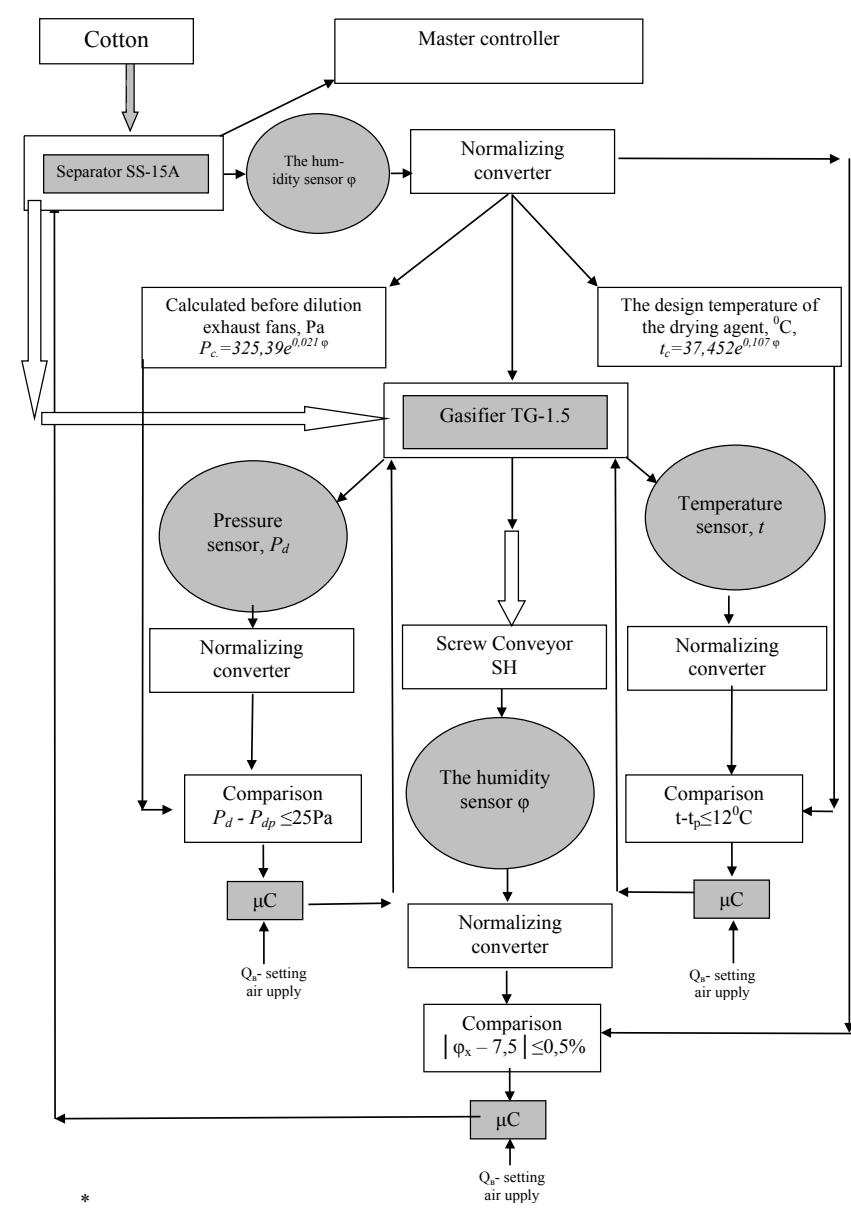

Figure 2: The control system ginning cotton.

The average error of approximation by the Fisher test is $2.5183 \%$, respectively; $1.2025 \%$ and $2.967 \%$.

These mathematical models (1-3) allow you to organize systematic management process of drying, cleaning and ginning cotton, providing the optimal mode of operation of equipment and machinery primary processing of cotton (Figures 1 and 2).

Parameters of the object (process cotton processing) are determined and controlled by technological dimensions. To provide automated control of cotton processing selected smart sensors "ZETLAV" for measuring temperature, humidity, current, pressure, and installed their main characteristics and wiring diagram of the measuring network. On the basis of selected technical means of measurements: sensors, measurement modules and inverters built block diagram of measuring instruments "ZETLAV" for measurement, control and testing process of cotton processing (Figures 3 and 4 ).

The measuring system "ZETLAV" provides simultaneous measurement (temperature, humidity, current, pressure) and the registration of all values of the measurement object. Measurement information generated by the sensors and transmitted as a measurement signal to the communication channel.

Depending on the type of the measured physical quantity, the operating principle of the sensor and the distance by which to transmit information of the measuring system can be incorporated intermediate

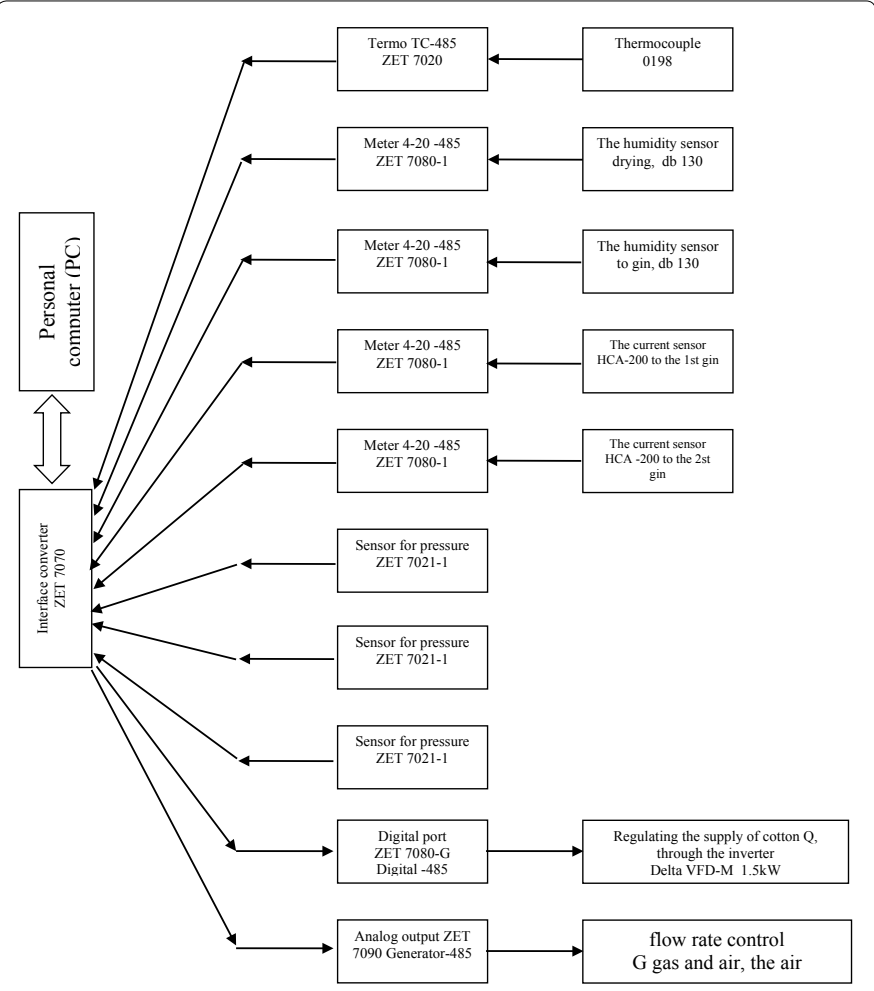

Figure 3: Block diagram of the measuring system " ZETLAV “.

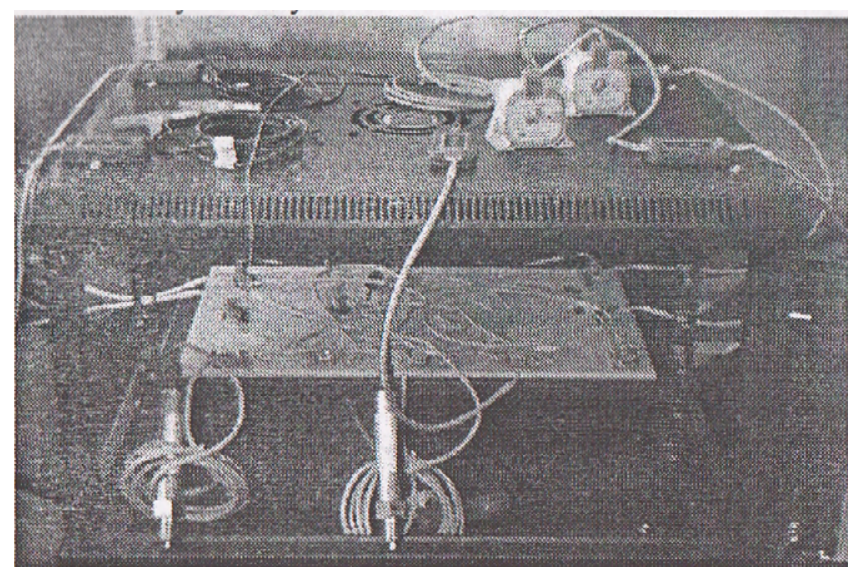

Figure 4: Scheme of the measuring system ZETLAV.

transducers (ZET 7020 TermoTS-485 intelligent sensor thermocouple TP-0198 interface I8-485 and universal sensors - HCA-200, d130 with current output) and the transmitting transducer ZET 7080-1. From the outputs of the transducers on the measuring signals received data transmission module 7070 ZET RS-485 USB, for processing measurement information on a predetermined algorithm and a physical interface associated with MS. Action on the object of monitoring and control is done via a digital port ZET 7060-G Digital-485 and analog output ZET 7090 Generator-485 - the actuator.

The package has ZETLAB drivers modules ZET 7070. Data Server ZETLAB automatically detects devices on the line RS- 485 reads the name of the measurement channel, the unit of measure, the upper and lower range of acceptable values of parameters and continuously reads the measuring channel and forms a continuous synchronized channel 
Citation: Rosulov RK, Muhamadiev DM (2015) Automated System for Operational Monitoring of Technological Processes in Cotton Enterprises. J Textile Sci Eng 5: 202. doi:10.4172/2165-8064.1000202

environment ZETLAB. Data server ZETLAB line scans for all available locations and in the case of a new device connects dynamically a new channel in the system. Upon detection of a new device ZET 7070 server also connects all the channels on the go. Thus, the line can be serviced without interrupting the work of other channels, ie, system allows "hot" replacement elements [4].

To ensure measurement, control and testing process of cotton processing adopted SCADA system ZETView. Using SCADA system ZETView, developed an electronic desk operator to control the process of drying, cleaning cotton ginneries and performance. The developed process control system implemented in the ginning process Bagat ginning plant.

\section{Reference}

1. Nikolaichuk OI (2003) Small automation system.

2. Belov MP, Novikov VA, Rassulov LN (2004) Automatic Electric model of industrial machinery and technological systems: Textbook for universities.

3. Augambay M, Ivanov AZ, Terekhov YT (1993) Basis for planning research experiment.

4. www.zetlab.ru 